\title{
2 段重複繰返応力に対する疲労強度*
}

河本実** 伊吹幸彥**

\section{Fatigue Strength of Steels under Multiple Repeated Stress in Two Stress Levels \\ Minoru KawAmoto and Yukihiko IBUKI}

In general, practical machine parts and structures are subjected to repeated stresses of various magnitudes. Therefore it is very important to know the effects of repeated stress with varying amplitude on the fatigue strength. Fatigue tests under the multiple repeated stress in two stress levels seem to be the most fundamental case. Then we made a research on the effect of the "primary stress" on the fatigue life of the "secondary stress."

In this research, three kinds of cabon steels--mild, medium and hard-have been tested by the Ono's rotating bending fatigue testing machine.

The results obtained are as follows.

1. In general, the theory that fatigue fracture occurs at $\sum \frac{n}{N}=1$ does not coincide with the experimental results.

2. It is convenient to represent the results of tests under multiple repeated stress by taking the equivalent number of cycles as the abscissa on S-N diagrams.

3. The S-N curves for the secondary stress bend at the place of the primary stress for the case of mild steel, but do not bend for the case of hard steel. For the case of medium steel, they bend when the primary stress is small, and do not bend when the primary stress is large.

4. When the primary stress is relatively small and the secondary stress is larger than the primary stress, the value of $\sum \frac{n}{N}$ is larger than 1 in most cases.

5. When the primary stress is relatively small and the secondary stress is smaller than the primary stress, the value of $\Sigma \frac{n}{N}$ is larger than 1 or nearly equal to 1 .

6. When the primary stress is relatively large and the secondary stress is larger than the primary stress, the value of $\Sigma \frac{n}{N}$ is nearly equal to 1 in most cases.

7. When the primary stress is relatively large and the secondary stress is smaller than the primary stress, the value of $\sum \frac{n}{N}$ is smaller than 1 in general, excluding the case when the secondary stress is a little smaller than the primary stress for mild and medium steels.

\section{1. 緒}

実際に和ける機械部分，または構造物の受ける繰返 応力は全寿命を通じて，その大きさが一定不变の場合 は稀であつて, 多くの場合, 作用する繰返応力はその 大きさが種々に変化するのが普通である。したがつて， 綝返応力の大きさが変化するととによつて, 疲労強度

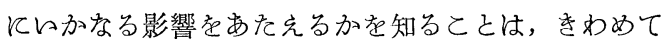
重要尔事柄である。そしてての变化する繰返応力の大 きさ, 種類, 繰返回数小よび順序につレては, その種 々な場合が考允られるが，その最も基礎的な場合と考

* 原稿受付 昭和 31 年 6 月 1 日

** 正員 京都大学工学部
えられる 2 段重複繰返応力, すなわち, 一定の繰返応 力がある回数作用した後, 大きさの異なる繰返応力が 引続き作用し，それが破嬉まで継続される場合につい て, 最初与える繰返応力によつて, 後に与える繰返応

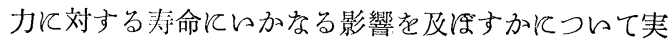
験的に求めようとするものである.

\section{2. 実 験 方 法}

実験供した材料は, 軟鋼, 半硬鋼扣よび硬鋼の 3 種の炭素鋼とし，熱処理するととなく供給状態のまま 使用した。 その化学成分扣よび機珹的性質をそれそそれ Table 1 和よび Table 2 亿示した。試駼機は小野式回 転曲げ疲学試験機を使用し, 毎分 2600 回転にて実験 
Table 1. Chemical composition of materials. (\%)

\begin{tabular}{l|c|c|c|c|c|c}
\hline Materials & Symbol & C & Si & Mn & P & S \\
\hline Mild steel & $232 \mathrm{~A}$ & 0.13 & 0.35 & 0.54 & 0.013 & 0.012 \\
Medium & 6426 & 0.34 & 0.24 & 0.48 & 0.016 & 0.028 \\
steel & $282 \mathrm{~B}$ & 0.63 & 0.13 & 0.73 & 0.041 & 0.025 \\
Hard steel & & & & & &
\end{tabular}

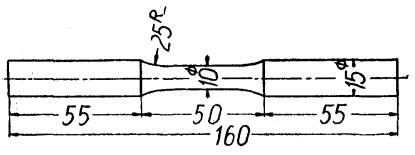

Fig. 1. Form of specimen.

Table 2. Mechanical properties of materials.

\begin{tabular}{|c|c|c|c|c|c|c|c|}
\hline Materials & Symbol & $\begin{array}{c}\text { Yield point } \\
\sigma s\left(\mathrm{~kg} / \mathrm{mm}^{2}\right)\end{array}$ & $\begin{array}{c}\text { Tensile } \\
\text { strength } \\
\sigma_{B}\left(\mathrm{~kg} / \mathrm{mm}^{2}\right)\end{array}$ & $\begin{array}{c}\text { Bieaking } \\
\text { strength on } \\
\text { final area } \\
\sigma_{T}\left(\mathrm{~kg} / \mathrm{mm}^{2}\right)\end{array}$ & $\begin{array}{c}\text { Elongation } \\
\varphi(\%)\end{array}$ & $\begin{array}{c}\text { Reduction } \\
\text { of area } \\
\psi(\%)\end{array}$ & $\begin{array}{c}\text { Hardness } \\
\text { Shore } \\
\text { Hs }\end{array}$ \\
\hline Mild steel & $282 \mathrm{~A}$ & $28 \cdot 5$ & $42 \cdot 5$ & $103 \cdot 5$ & $33 \cdot 5$ & $69 \cdot 3$ & $17 \cdot 0$ \\
\hline Midium steel & 6426 & $31 \cdot 8$ & $55 \cdot 3$ & $89 \cdot 9$ & $22 \cdot 6$ & $48 \cdot 5$ & $21 \cdot 0$ \\
\hline Hard steel & $282 \mathrm{~B}$ & $45 \cdot 7$ & $81 \cdot 1$ & $107 \cdot 9$ & $17 \cdot 8$ & $31 \cdot 1$ & $27 \cdot 0$ \\
\hline
\end{tabular}

を行つを. 試験片の形状寸法をFig. 1 亿示した。

実験は 3 種の材料に詨し，それぞれまず隹通の疲労 試験を行々， $S-N$ 曲線を決定し, ついで, 1 次応力, すなわち最初与える絽返応力として, もし, 一定の繰 返応力を与えたならば $10^{5}$ 和よひ $10^{6}$ の繰返数にて破 壞するような応力をとり，乙の繰返応力をそれそれそ の寿命の $50 \%$ 执よび $80 \%$ 亿相当する繰返数だけ作用せ しめそ後, 綠返応力の大きさを種々に变えて破壞まで 実験を行つた。な抏，いずれの実験についてもそれぞ れ 1 本の素材より試験片を切り出した。

\section{3. 実験結果の図示法について}

実験の結果を表わす方法として, 次に述べる二つの 方法をもつて示した。

（i）第 1 法乙れは 1 次応力をある繰返数だけ 与えた材料を処女材料と見交して，もとの処女材料の $S-N$ 曲線の上飞重水て画く方法である。 Fig. 2 に和い て 1 次応力を $\sigma_{1}$ とし， $\sigma_{1}$ 亿扣ける破壊までの繰返数 を $N_{1}$ とする。だし, 図の横軸は対数目盛で示した ものとする。いま, $\sigma_{1}$ でA点まで，すなわち， $i N_{1}$ だ け綝返した材料を処女材料と見なして疼労試験した場 合の結果を表わす $S-N$ 曲線について考える.もし, 2 次応力を 1 次応力と同じ $\sigma_{1}$ 亿等しくした場合には， 2 次応力の繰返数 $(1-i) N_{1}$ にて破壊する筈であるから, 求める $S-N$ 曲線はB点趋るととは当然である. 次 飞2 次応力を $\sigma_{2}$ とした場合， $\sigma_{2}$ に和ける処女材料の

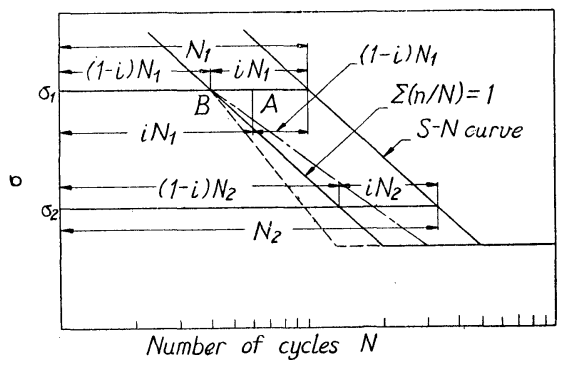

Fig. 2. The 1st method.
破壊までの繰返数を $N_{2}$ とすれば，らまもし，材料が 繰返数比積算法, すなわち, 任意の応力繰返数をその 応力の下に和ける破㯖までの繰返数にて除した值の累 計が 1 亿達した $\left(\sum \frac{n}{N}=1\right)$ とき, 疲学破壊を起とすと 的考え方従うものとすれば，2次応力 $\sigma_{2}$ による 破壊までの繰返数は (1-i) $N_{2}$ でなければならない。し そがつて, 求める $S-N$ 曲線の傾斜部は $\mathrm{B}$ 点を通り元 の $S-N$ 曲線の傾斜部に平行な線となる. 換言すれば,

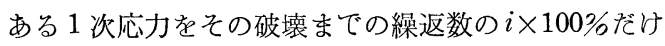
与えた材料に対する $S-N$ 曲線は処女材料の $S-N$ 曲線 を $i \times 100 \%$ け水平に左にずらした曲線となる。した がつて, もし 2 次応力の破壊までの繰返数が $\Sigma \frac{n}{N}=1$ より求められる值より小であれば破線で示したように 平行線より左側飞き，また，反対に大となれば鎖線で 示したように平行線より右側にくるとととなる。な执， 積算繰返数比が一定值になつたとを破壊を起とすもの とすれば，2次応力に対与る耐久限度は常に処女材料 の耐久限度に等しくなる。

（ii）第 2 法 この方法は 1 次応力を与えた材料を 処女材料と見なさず, 1 次応力にて与えた繰返数比と 等しい繰返数比だけの 2 次応力をすでに与えたものと 考え, その上に実際 2 次応力にて与える繰返数を累加 して表わす方法である。乙の累加された繰返数を換算 繰返数と呼ぶこととする。 らま, Fig. 3 亿扣いて 1 次 応力 $\sigma_{1}$ を $i N_{1}$ だけ,すなわち $\mathrm{A}$ 点まで繰返し, つレで

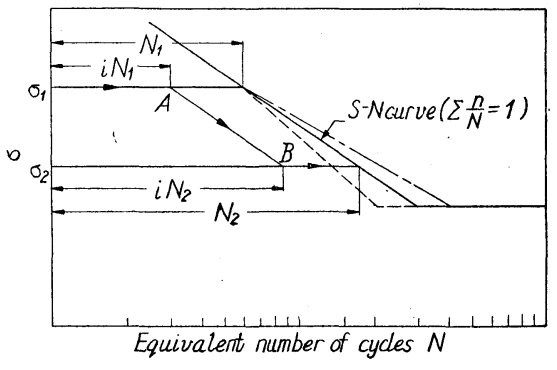

Fig. 3. The 2 nd method. 
2 次応力 $\sigma_{2}$ 亿切り換えたものとする. 1 次応力飞与元 そ繰返数比と同じ絽返数比 $i$ 亿相当する 2 次応力上の 点はB点である。ただし，横軸は対数目盛とすれば $\mathrm{A}$ $\mathrm{B}$ はもとの $S-N$ 曲線に平行である. 2 次応力にて与 える繰返数はB点より右に測つて加える。すなわち, 換算繰返数をもつて表わす。もし, 材料が $\sum \frac{n}{N}=1$ な る条件に従うものとすれば破壞はもとの $S-N$ 曲線上
で起とる筈であり，てれより寿命が小ならば破線のよ らになり，反対に大ならば鎖線のようとなる。しれが つて, 実験結果を $\sum \frac{n}{N}=1$ 亿よる結果と比較する場合, その比較が一目膫然となる。従来との方法によつて表 わされた例は見当らないが，筆者はとの方法が非常に 解りやすく，有用なるすのと信じととに提案する次第 である。

Table 3. Mild steel (at low primary stress).

\begin{tabular}{|c|c|c|c|c|c|c|c|}
\hline \multirow[t]{2}{*}{ No. } & \multicolumn{2}{|c|}{$\begin{array}{c}\text { Repeated stress } \\
\left(\mathrm{kg} / \mathrm{mm}^{2}\right)\end{array}$} & \multicolumn{2}{|c|}{ Number of cycles } & \multirow{2}{*}{$\begin{array}{c}\text { Equivalent } \\
\text { number of cycles } \\
n_{1} \frac{N_{2}}{N_{1}}+n_{2}\end{array}$} & \multirow{2}{*}{$\begin{array}{l}\text { Cumulative } \\
\text { cycle ratio } \\
\qquad \sum \frac{n}{N}\end{array}$} & \multirow[t]{2}{*}{ Remarks } \\
\hline & Primary & Secondary & Primary $n_{1}$ & Secondary $n_{2}$ & & & \\
\hline A 1 & 34 & - & 231000 & & & $1 \cdot 0$ & \\
\hline A 21 & 32 & - & 353500 & & & $1 \cdot 0$ & \\
\hline A 5 & 30 & - & 541500 & & & $6 \cdot 797$ & \\
\hline A 18 & $29 \cdot 1$ & - & 664800 & & & 0.665 & \\
\hline A 2 & 29 & - & 1202500 & & & $1 \cdot 17$ & \\
\hline A 19 & 29 & - & 1430000 & & & $1 \cdot 39$ & \\
\hline A 20 & 28 & - & 2069200 & & & $1 \cdot 035$ & \\
\hline A 7 & 28 & - & 5564600 & & & $2 \cdot 78$ & \\
\hline A 25 & $27 \cdot 5$ & - & 3101100 & & & 0.97 & \\
\hline A 11 & $27 \cdot 5$ & - & 1019000 & & & $0 \cdot 318$ & \\
\hline A 6 & 27 & - & 4182400 & & & 0.697 & \\
\hline A 16 & 26 & - & 10077500 & & & & Not broken \\
\hline A 17 & $29 \cdot 1$ & 34 & 500000 & 340000 & 455500 & $1 \cdot 97$ & \\
\hline $\mathrm{A} 12$ & $29 \cdot 1$ & 32 & 500000 & 336500 & 513200 & $1 \cdot 45$ & \\
\hline A 22 & $29 \cdot 1$ & 30 & 500000 & 550300 & 890300 & $1 \cdot 31$ & \\
\hline A 24 & $29 \cdot 1$ & 30 & 500000 & 535700 & 875700 & $1 \cdot 19$ & \\
\hline A 3 & $29 \cdot 1$ & 28 & 500000 & 9015000 & $10015 \smile 00$ & & Not broken \\
\hline $\mathrm{A} 27$ & $29 \cdot 1$ & 27 & 500000 & 8187700 & 11187700 & $1 \cdot 86$ & \\
\hline A 26 & $29 \cdot 1$ & 34 & 800000 & 171700 & 356500 & $1 \cdot 54$ & \\
\hline A 4 & $29 \cdot 1$ & 32 & 800000 & 1200700 & 1483500 & $4 \cdot 2$ & \\
\hline A 9 & $29 \cdot 1$ & 30 & 800000 & 3493200 & 4037200 & $4 \cdot 93$ & \\
\hline A 14 & $29 \cdot 1$ & 30 & 800000 & 1301310 & 1845300 & $2 \cdot 72$ & \\
\hline A 23 & $29 \cdot 1$ & 28 & 800000 & 1392000 & 2992000 & $1 \cdot 495$ & \\
\hline A 8 & $29 \cdot 1$ & 27 & 800000 & 4528900 & 9328000 & $1 \cdot 55$ & \\
\hline
\end{tabular}

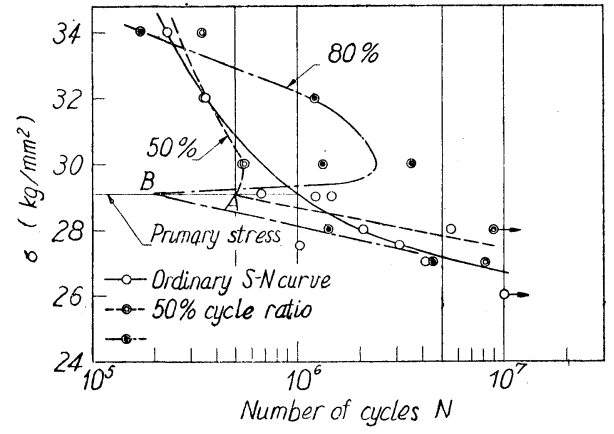

Fig. 4. Results on mild steel under low. primary stress (1 st method).

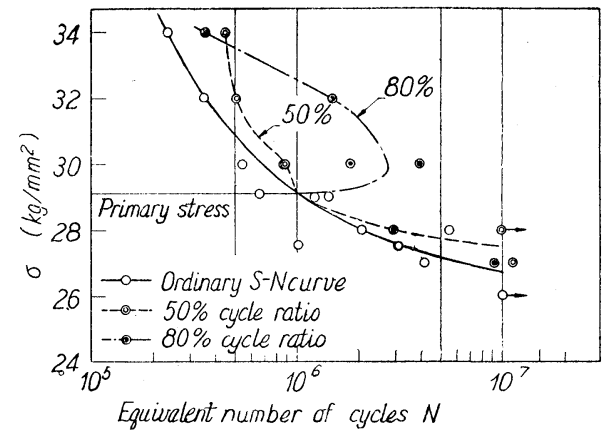

Fig. 5. Results or mild steel under low primary stress (2nd method). 


\section{4. 実験結果およびその考察}

\section{1 軟 鋼}

a. 1 次応カが比較的小なる場合 1 次応力が比較 的小さい場合 $\left(29.1 \mathrm{~kg} / \mathrm{mm}^{2}\right)$ 対する実験結果支 Table 3 亿示した。とれを図示したものが Fig. 4 执よ び Fig. 5 である，Fig. 4 は第 1 法により，Fig. 5 は第 2 法により描いたものである。

Fig. 4 亿扣々て第 1 次応力の下に扣ける破壊までの 繰返数は $1 \times 10^{6}$ であるから，1 次応力を $50 \%$ あるい は $80 \%$ 与えた場合の破壞までの繰返数は，もし2 次応 力が 1 次応力に等しければ，それぞれ $0.5 \times 10^{6}$ ある 々は $0.2 \times 10^{6}$ となる筈である。すなわち, 図のA打 よでB点にて表わされる。したがつて，1次応力を繰 返数比 $50 \%$ あるいは $80 \%$ 与えた材料の $S-N$ 曲線は， それぞれA执よどB点を過ざるととは明らかで，図の 破線执よひ鎖線で示しそようになる。この結果より 1 次応力をある程度与えた材料を処女材料とみなした場 合の $S-N$ 曲線は決して滑らかな曲線とならず， 1 次 応力の位置飞狲らていちじるしく屈曲した曲線となる ことがわかり，乙れは特に注目すべきととである。な 和, 2 次応力が 1 次応力より少し大をく, かつ繰返数
比 $80 \%$ の場合，破壊までの繰返数はいちじるしく大で， 材料は 1 次応力によつて何ら被慧を受けていないのみ か，かえつて強化せしめられていることがわかる。

次に，矢験結果を $\sum \frac{n}{N}=1$ 亿よる結果と比較すると， Fig. 5 より 2 次応力が 1 次応力より大なると小なると 飞かかわらす，常に $\sum \frac{n}{N}>1$ なるととがわかる。殊飞， 2 次応力が 1 次応力より少しく大で, かつ, 1 次応力 の繰返数比が $80 \%$ のきは $\sum \frac{n}{N}$ はらちじるしく大で, Table 3 よりかかるように $\sum \frac{n}{N}$ は最大 4.93 に達して レる.

b. 1 次応力が比較的大なる場合 1 次応力が比較 的大子る場合 $\left(32.5 \mathrm{~kg} / \mathrm{mm}^{2}\right)$ 対する実験結果支 Table 4 亿示した。 これを図示したものが Fig. 6 扣 よび Fig. 7 である. Fig. 6 は第 1 法により，Fig. 7 は 第 2 法により描いたものである。ます，Fig. 6 を見る 飞 1 次応力を与えた材料の $S-N$ 曲線が 1 次応力の位 置にてらちじるしく屈曲した曲線となるととは前と同 様である。な抹，Fig. 7 より明らかなよ 5 亿2 次応力 が 1 次応力より大なるときは $\sum \frac{n}{N}>1$ となり， 2 次応 力が 1 次応力より小なるときは概して $\sum \frac{n}{N}<1$ とな

Table 4. Mild steel (at high primary stress).

\begin{tabular}{|c|c|c|c|c|c|c|c|}
\hline \multirow[t]{2}{*}{ No. } & \multicolumn{2}{|c|}{$\begin{array}{c}\text { Repeated stress } \\
\left(\mathrm{kg} / \mathrm{mm}^{2}\right)\end{array}$} & \multicolumn{2}{|c|}{ Number of cycles } & \multirow{2}{*}{$\begin{array}{c}\text { Equivalent } \\
\text { number of cycles } \\
n_{1} \frac{N_{2}}{N_{1}}+n_{2}\end{array}$} & \multirow{2}{*}{$\begin{array}{l}\text { Cumulative } \\
\text { cycle ratio } \\
\qquad \sum \frac{n}{N}\end{array}$} & \multirow[t]{2}{*}{ Remarks } \\
\hline & Primary & Secondary & Primary $n_{1}$ & Secondary $n_{2}$ & & & \\
\hline A 36 & 34 & 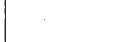 & 32500 & & & $0 \cdot 903$ & \\
\hline A 47 & 33 & , & 108000 & & & $1 \cdot 405$ & \\
\hline A 42 & $32 \cdot 5$ & & 72860 & & & $0 \cdot 728$ & \\
\hline $\mathrm{A} 41$ & 32 & & 82000 & & & $0 \cdot 656$ & \\
\hline A 32 & 32 & & 217000 & & & $1 \cdot 74$ & \\
\hline A 46 & 30 & & 394500 & & & $1 \cdot 11$ & \\
\hline A51 & 28 & & 1024500 & & & $1 \cdot 025$ & \\
\hline A31 & 27 & & 1448400 & & & $0 \cdot 843$ & \\
\hline A56 & 26 & & $263500 \mathrm{CO} 0$ & & & & Not broken \\
\hline A49 & $32 \cdot 5$ & 34 & 50000 & 41500 & 64500 & $1 \cdot 40$ & \\
\hline A 44 & $32 \cdot 5$ & 33 & 50000 & 75500 & 114100 & $1 \cdot 48$ & \\
\hline A39 & $32 \cdot 5$ & 32 & 50000 & 99000 & 161500 & $1 \cdot 29$ & . \\
\hline A 53 & $32 \cdot 5$ & 30 & 50000 & 115600 & 293600 & 0.825 & \\
\hline A 48 & $32 \cdot 5$ & 28 & 50000 & 308700 & 808700 & 0.809 & \\
\hline $\mathrm{A} 34$ & $32 \cdot 5$ & 27 & $50 \mathrm{CO0}$ & 372400 & 1222400 & $0 \cdot 72$ & \\
\hline A 35 & $32 \cdot 5$ & 26 & 50000 & 7.16000 & 2096000 & $0 \cdot 775$ & \\
\hline A37 & $32 \cdot 5$ & 34 & 80000 & 32700 & 69.500 & $1 \cdot 51$ & \\
\hline A 43 & $32 \cdot 5$ & 33 & 80000 & 21000 & 82600 & $1 \cdot 07$ & \\
\hline A57 & $32 \cdot 5$ & 32 & 80000 & 298000 & 398000 & $3 \cdot 18$ & \\
\hline A 33 & $32 \cdot 5$ & 30 & 80900 & 189500 & 474300 & $1 \cdot 33$ & \\
\hline A 38 & $32 \cdot 5$ & 28 & 80000 & 78500 & 878500 & $0 \cdot 879$ & \\
\hline A 52 & $32 \cdot 5$ & 27 & 80000 & 561000 & 1921000 & $1 \cdot 13$ & \\
\hline A54 & $32 \cdot 5$ & 26 & 80000 & 500600 & 2660600 & 0.986 & \\
\hline
\end{tabular}




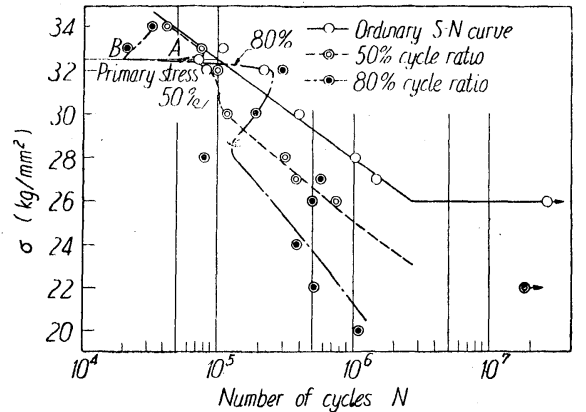

Fig. 6. Results on mild steel under high primary stress (1 st method).

る。をだし， 2 次応力が 1 次応力より小で，かつそ の差が小さいとをは $\Sigma \frac{n}{N}>1$ となる。また， 1 次応力 の繰返数比が80\%の場合の方が50\%の場合よりも $\Sigma \frac{n}{N}$

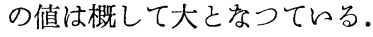

\section{2 半硬鋼}

a. 1 次応力が比較的小なる場合 1 次応力が比較

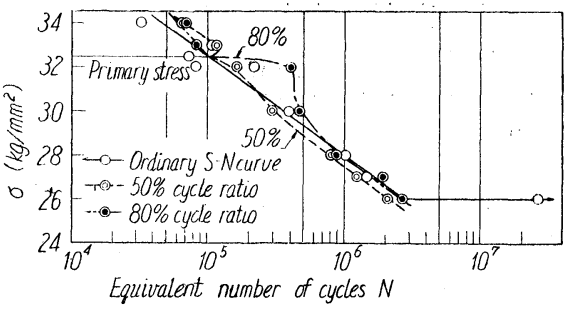

Fig. 7. Results on mild steel under high primary stress (2nd method).

的小なる場合 $\left(23.5 \mathrm{~kg} / \mathrm{mm}^{2}\right)$ 飞対する実験結果を Table 5 亿示した。乙れを図示したものが Fig. 8 和よ びFig.9である.Fig. 8 注第1 法により，Fig.9 は第 2 法により描らをものである。すす，Fig. 8 を見ると 1 次応力を与えた材料の $S-N$ 曲線が 1 次応力の位置に ていちじるしく屈曲した曲線となつているととは前と 同様で，な和， 2 次応力による破壊をでの繰返数は概 して元の $S-N$ 曲線の示す絽返数より大となつて和り，

Table 5. Medium steel (at low primary stress).

\begin{tabular}{|c|c|c|c|c|c|c|c|}
\hline \multirow[t]{2}{*}{ No. } & \multicolumn{2}{|c|}{$\begin{array}{c}\text { Repeated stress } \\
\left(\mathrm{kg} / \mathrm{mm}^{2}\right)\end{array}$} & \multicolumn{2}{|c|}{ Number of cycles } & \multirow{2}{*}{$\begin{array}{c}\text { Equivalent } \\
\text { number of cycles } \\
n_{1} \frac{N_{2}}{N_{1}}+n_{2}\end{array}$} & \multirow{2}{*}{$\begin{array}{c}\text { Cumulative } \\
\text { cycle ratio } \\
\Sigma \Sigma \frac{n}{N} \\
\end{array}$} & \multirow[t]{2}{*}{ Remarks } \\
\hline & Primary & Secondary & Primary $n_{1}$ & Secondary $n_{2}$ & & & \\
\hline C 1 & 32 & & 27500 & \multirow{12}{*}{. } & & $0 \cdot 81$ & \multirow{12}{*}{$\begin{array}{l}\text { Not broken } \\
\text { Not broken } \\
\text { Not broken } \\
\text { Not broken }\end{array}$} \\
\hline C 6 & 30 & & 58500 & & & $0 \cdot 791$ & \\
\hline $\mathrm{C} 27$ & 30 & & 88100 & & & $1 \cdot 19$ & \\
\hline $\mathrm{C} 17$ & 28 & & 214.000 & & & $1 \cdot 336$ & \\
\hline C11 & 26 & & 336700 & & & 0.935 & \\
\hline $\mathrm{C} 16$ & 24 & & 765600 & & & 0.93 .4 & \\
\hline C 2 & 23 & & 1439200 & & & $1 \cdot 179$ & \\
\hline $\mathrm{C} 21$ & 22 & & 2968500 & & & $1 \cdot 63$ & \\
\hline $\mathrm{C} 10$ & 22 & & 12000000 & & & & \\
\hline $\mathrm{C} 12$ & $21 \cdot 5$ & & 11200000 & & & & \\
\hline C 7 & 21 & & 11925700 & & & & \\
\hline $\mathrm{C} 26$ & 20 & & 12745000 & & & & \\
\hline C 5 & $23 \cdot 5$ & 32 & 500000 & $420 C 0$ & 58000 & $1 \cdot 811$ & \multirow[b]{7}{*}{ Not broken } \\
\hline C 8 & $23 \cdot 5$ & 30 & 500000 & 77500 & 114000 & $1 \cdot 562$ & \\
\hline $\mathrm{C} 13$ & $23 \cdot 5$ & 28 & 500000 & 152000 & 230000 & $1 \cdot 437$ & \\
\hline $\mathrm{C} 22$ & $23 \cdot 5$ & 26 & 500000 & 490000 & 670000 & $1 \cdot 86$ & \\
\hline $\mathrm{C} 28$ & $23 \cdot 5$ & 24 & 500000 & 1265500 & 1675500 & $2 \cdot 044$ & \\
\hline C 3 & $23 \cdot 5$ & 23 & 500000 & 2280000 & 2890000 & $2 \cdot 368$ & \\
\hline $\mathrm{C} 18$ & $23 \cdot 5$ & 22 & 500000 & 10790000 & 11700000 & & \\
\hline $\mathrm{C} 29$ & $23 \cdot 5$ & 32 & 800000 & 47000 & 72600 & $2 \cdot 266$ & \\
\hline C 19 & $23 \cdot 5$ & 30 & 800000 & 81500 & 139900 & $1 \cdot 915$ & \\
\hline $\mathrm{C} 23$ & $23 \cdot 5$ & 28 & 800000 & 232000 & 360000 & $2 \cdot 25$ & \\
\hline C 4 & $23 \cdot 5$ & 26 & 800000 & 591000 & 879000 & $2 \cdot 44$ & \\
\hline C 9 & $23 \cdot 5$ & 24 & 800000 & 845000 & 1501000 & $1 \cdot 832$ & \\
\hline $\mathrm{C} 14$ & $23 \cdot 5$ & 23 & 800000 & 1975000 & 2951000 & $2 \cdot 42$ & \\
\hline $\mathrm{C} 24$ & $23 \cdot 5$ & 22 & 800000 & 14500000 & 15956000 & & Not broken \\
\hline
\end{tabular}




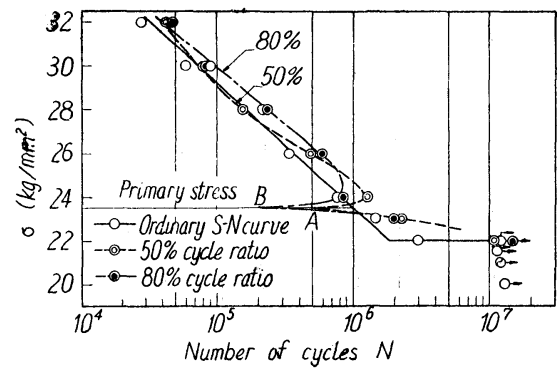

Fig. 8. Results on medium steel under low primary stress (1 st method).

材料は 1 次応力によつてかえつて強化せしめられてい ることがかかる. 次に $\sum \frac{n}{N}$ の值については, Fig. 9 より明らかなように，2次応力の大きさのいかんにか かわらず, 常飞 $\sum \frac{n}{N}>1$ となつており, 1 次応力の繰

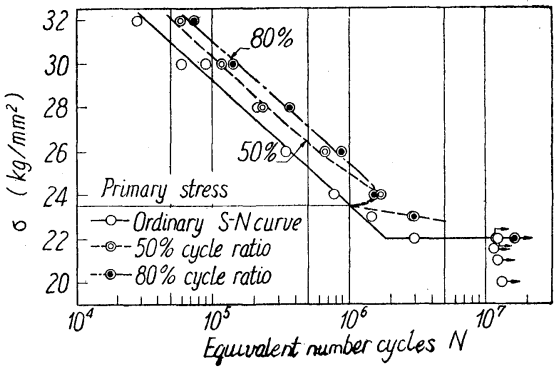

Fig. 9. Results on medium steel under low primary stress (2nd method).

返数比が $80 \%$ の場合の方が $50 \%$ 場合よりも $\Sigma \frac{n}{N}$ の 值は概して大きい.

b. 1 次応力が比較的大なる場合 1 次応力が比較 的大き々場合 $(30 \mathrm{~kg} / \mathrm{mm})$ 亿対する実験結果をTable 6

Table 6. Medium steel (at high primary stress).

\begin{tabular}{|c|c|c|c|c|c|c|c|}
\hline \multirow[t]{2}{*}{ No. } & \multicolumn{2}{|c|}{$\begin{array}{c}\text { Repeated stress } \\
\left(\mathrm{kg} / \mathrm{mm}^{2}\right)\end{array}$} & \multicolumn{2}{|c|}{ Number of cycles } & \multirow{2}{*}{$\begin{array}{c}\text { Equivalent } \\
\text { number of cycles } \\
n_{1} \frac{N_{2}}{N_{1}}+n_{2}\end{array}$} & \multirow{2}{*}{$\begin{array}{c}\text { Cumulative } \\
\text { cycle ratio } \\
\qquad \Sigma \frac{n}{N}\end{array}$} & \multirow[t]{2}{*}{ Remarks } \\
\hline & Primary & Secondary & Primary $n_{1}$ & Secondary $n_{2}$ & & & \\
\hline $\mathrm{C} 40$ & 34 & & 20000 & & & $1 \cdot 665$ & \\
\hline $\mathrm{C} 46$ & 32 & & 28700 & & & $0 \cdot 845$ & \\
\hline $\mathrm{C} 32$ & 30 & & 95000 & & & 0.95 & \\
\hline $\mathrm{C} 47$ & 30 & & 37000 & & & 0.37 & \\
\hline C 38 & 36 & & 79000 & & & $0 \cdot 79$ & \\
\hline $\mathrm{C} 43$ & 30 & & 64000 & & . & $G \cdot 64$ & \\
\hline C39 & 30 & & 68000 & & & $0 \cdot 68$ & \\
\hline $\mathrm{C} 44$ & 30 & & 53000 & & & 0.53 & \\
\hline $\mathrm{C} 49$ & 30 & & 47000 & & & 0.47 & \\
\hline $\mathrm{C} 41$ & 28 & & 241600 & & & 0.805 & \\
\hline $\mathrm{C} 56$ & 26 & & 1243000 & & & $1 \cdot 38$ & \\
\hline C 36 & 24 & & 2700000 & & & $1 \cdot 0$ & \\
\hline C51 & 23 & & 5228000 & & & $1 \cdot 136$ & \\
\hline C 31 & 22 & & 10780000 & & & & Not broken \\
\hline $\mathrm{C} 45$ & 30 & 34 & 50000 & 3000 & 9000 & $0 \cdot 75$ & \\
\hline $\mathrm{C} 33$ & 30 & 32 & 50000 & 26500 & 43500 & $1 \cdot 28$ & \\
\hline $\mathrm{C} 57$ & 30 & 28 & 50000 & 50860 & $200 \& 00$ & $0 \cdot 67$ & \\
\hline $\mathrm{C} 52$ & 30 & 26 & $500 C 0$ & 3800 & 453800 & 0.504 & \\
\hline $\mathrm{C} 42$ & 30 & 24 & 50000 & 59000 & 1409000 & 0.522 & \\
\hline $\mathrm{C} 37$ & 30 & 23 & 50000 & 149000 & 2449000 & 0.533 & \\
\hline $\mathrm{C} 59$ & 30 & 22 & 50000 & 340000 & $434 \mathrm{C} 000$ & 0.543 & \\
\hline $\mathrm{C} 60$ & 30 & 21 & $500 c 0$ & 13820000 & & & Not broken \\
\hline $\mathrm{C} 50$ & 30 & 34 & 80000 & 9500 & 19100 & $1 \cdot 59$ & \\
\hline $\mathrm{C} 54$ & $s 0$ & 32 & 80000 & 3000 & 275000 & 0.809 & \\
\hline C 34 & 30 & 28 & 80000 & 103800 & 343800 & $1 \cdot 143$ & \\
\hline $\mathrm{C} 58$ & 30 & 26 & 80000 & 33900 & 753900 & 0.837 & \\
\hline $\mathrm{C} 53$ & 30 & 24 & $800 C 0$ & 123000 & 2283000 & 0.847 & \\
\hline $\mathrm{C} 48$ & 30 & 23 & 80000 & 17300 & 3697300 & 0.803 & \\
\hline C35 & 30 & 22 & 80000 & 155000 & $6555 c 00$ & 0.82 & \\
\hline $\mathrm{C} 55$ & 30 & 21 & 80000 & 296800 & & & \\
\hline
\end{tabular}




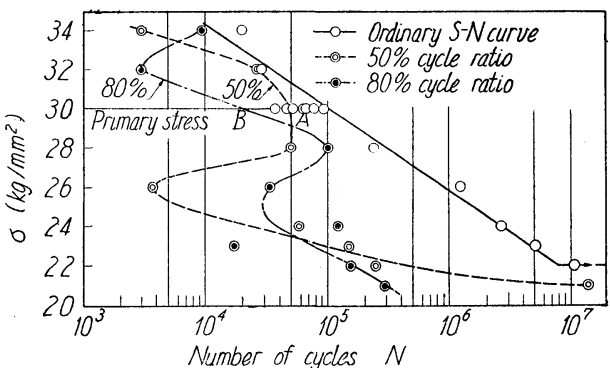

Fig. 10. Results on medium steel under high primary stress (1 st method).

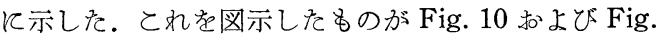
11 である。Fig. 10 は第 1 法により,Fig. 11 は第 2 法 により描いてものである。ますＦig. 10 を見るに，実 験結果はかなりばらついているよらに思われるので， 確かなととはわからないが，前節までにおけるように 1 次応力を与えた材料の $S-N$ 曲線が 1 次応力の位置 スていちじるしく屈曲するようなととは見られない。 な执，Fig. 11 より明らかなよに，2次応力が 1 次

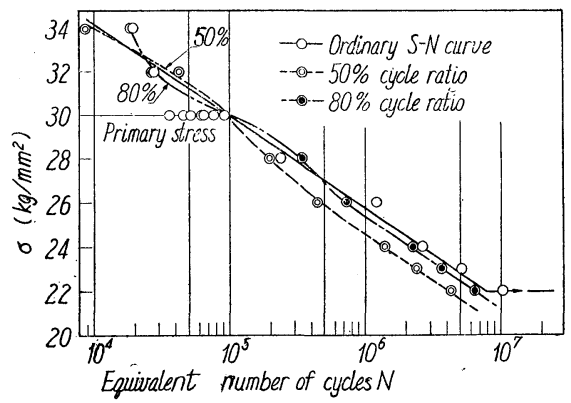

Fig. 11. Results on medium steel under high primary stress (2nd method).

応力よりも大なるときは $\sum \frac{n}{N} \fallingdotseq 1$ となり，2 次応力が 1 次応力よりも小なるときは概して $\sum \frac{n}{N}<1$ となる. だし，繰返数比が $80 \%$ の場合で，2次応力が 1 次応 力よりもわずかに小さいとをは $\sum \frac{n}{N}>1$ となるとと， および 1 次応力の繰返数比が $80 \%$ の場合の方が $50 \%$ の 場合よりも $\sum \frac{n}{N}$ の值は概して大となつているととな ぞは軟鋼の場合に類似している。

Table. 7 Hard steel (at low primary stress).

\begin{tabular}{|c|c|c|c|c|c|c|c|}
\hline \multirow[t]{2}{*}{ No. } & \multicolumn{2}{|c|}{$\begin{array}{c}\text { Repeated stress } \\
\left(\mathrm{kg} / \mathrm{mm}^{2}\right)\end{array}$} & \multicolumn{2}{|c|}{ Number of cycles } & \multirow{2}{*}{$\begin{array}{c}\text { Equivalent } \\
\text { Number of cycles } \\
n_{1} \frac{N_{2}}{N_{1}}+n_{2}\end{array}$} & \multirow{2}{*}{$\begin{array}{l}\text { Cumulative } \\
\text { cycle ratio } \\
\qquad \frac{n}{N}\end{array}$} & \multirow[t]{2}{*}{ Remarks } \\
\hline & Primary & |Secondary & Primary $n_{1}$ & Secondary $n_{2}$ & & & \\
\hline B 1 & 34 & & 176300 & & & $1 \cdot 1$ & \\
\hline $\mathrm{B} 21$ & 33 & & 306000 & & 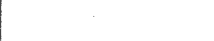 & $1 \cdot 054$ & \\
\hline B 6 & 32 & & 447000 & & & 0.828 & \\
\hline B17 & 31 & & 693500 & & & 0.694 & \\
\hline B 3 & 31 & . & 768400 & & & 0.768 & \\
\hline B18 & 31 & & 742200 & & & $0 \cdot 742$ & \\
\hline B 4 & 31 & & 624100 & & & 0.624 & \\
\hline В 9 & 31 & & 684700 & & & 0.685 & \\
\hline B 22 & $30 \cdot 5$ & & 1533700 & & & $1 \cdot 134$ & \\
\hline B11 & 30 & & 2043460 & & & $1 \cdot 11$ & \\
\hline B 7 & $29 \cdot 5$ & & 2248500 & & & 0.9 & \\
\hline B16 & 29 & & 10000000 & & 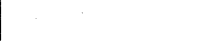 & & Not broken \\
\hline B12 & 31 & 34 & 500000 & 41100 & 121100 & $0 \cdot 758$ & \\
\hline B 5 & 31 & 33 & 500000 & 158700 & 303700 & $1 \cdot 045$ & \\
\hline $\mathrm{B} 20$ & 31 & 33 & 500000 & 63500 & 208500 & 0.72 & \\
\hline B10 & 31 & 32 & 500000 & 13500 & 283500 & 0.525 & \\
\hline B15 & 31 & $30 \cdot 5$ & 500000 & 1102500 & 1777500 & $1 \cdot 316$ & \\
\hline B 2 & 31 & 30 & 500000 & 541800 & 1461800 & $0 \cdot 795$ & \\
\hline B25 & 31 & $29 \cdot 5$ & 500000 & 6960000 & 8210000 & $3 \cdot 28$ & \\
\hline B 8 & 31 & 34 & 800000 & 58500 & 176500 & $1 \cdot 1$ & \\
\hline B 9 & 31 & 33 & 800000 & 190100 & 422100 & $1 \cdot 456$ & \\
\hline B23 & 31 & 32 & 800000 & 211000 & 643000 & $1 \cdot 19$ & \\
\hline B14 & 31 & $30 \cdot 5$ & 800000 & 158400 & 1238400 & 0.917 & \\
\hline B24 & 31 & 30 & 800000 & 166700 & 1638700 & 0.89 & \\
\hline $\mathrm{B} 13$ & 31 & $29 \cdot 5$ & 800000 & 882000 & 882000 & $1 \cdot 15$ & \\
\hline
\end{tabular}




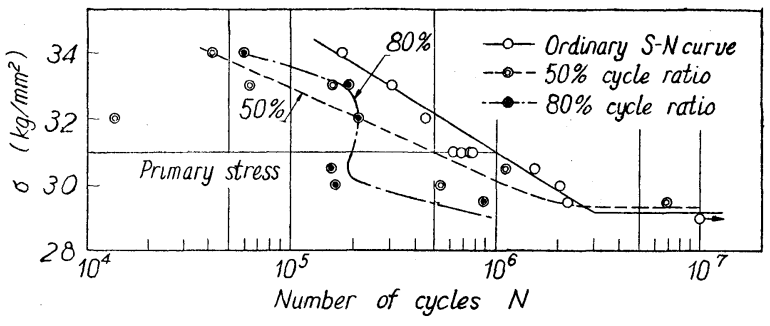

Fig. 12. Results on hard steel under low primary stress (1st method).

\section{3 硬 鋼}

a. 1 次応力が比較的小なる場合 1 次応力が比較 的小なる場合 $\left(31.0 \mathrm{~kg} / \mathrm{mm}^{2}\right)$ K対する実験結果を Table 7 亿示した。 とれを図示したものが Fig. 12 お よび Fig. 13 である. Fig. 12 第 1 法により, Fig. 13 は第 2 法により描らたものである。まず, Fig. 12 を 見るに，乙の場合もやはり 1 次応力を与えた材料の $S-N$ 曲線が 1 次応力の位置に排いていちじるしく屈曲 するととは見られない. また，Fig. 13 より， $\Sigma \frac{n}{N}$ の

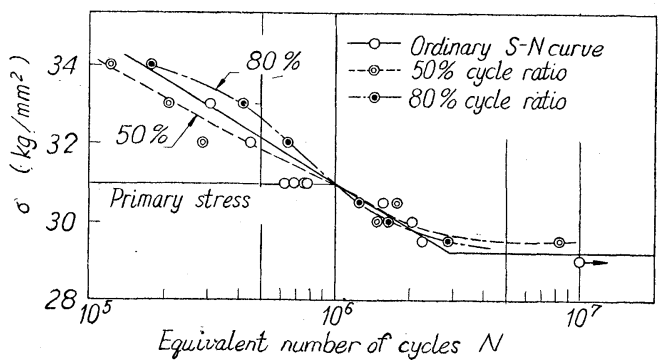

Fig. 13. Results on hard steel under low primary stress (2nd method).

值は 2 次応力の大ささのいかんにかかわらす，だいた 的 $\sum \frac{n}{N} \div 1$ と見ることがでをるよらであるが，詳細炕 みれば， 2 次応力が 1 次応力よりも大なる場合で，絽 返数比 $80 \%$ のとは $\sum \frac{n}{N}>1$ となり，繰返数比 $50 \%$ の とをは $\sum \frac{n}{N}<1$ となつている。

b. 1 次応力が比較的大なる場合 1 次応力が比較 的大きい場合 $\left(38.0 \mathrm{~kg} / \mathrm{mm}^{2}\right)$ 飞対する実験結果を Table 8 亿示した。これを図示したものが Fig. 14 利

Trble 8. Hard steel (at high primary stress).

\begin{tabular}{|c|c|c|c|c|c|c|c|}
\hline \multirow[t]{2}{*}{ No. } & \multicolumn{2}{|c|}{$\begin{array}{c}\text { Repeatted stress } \\
\left(\mathrm{kg} / \mathrm{mm}^{2}\right)\end{array}$} & \multicolumn{2}{|c|}{ Number of cycles } & \multirow{2}{*}{$\begin{array}{l}\text { Equivalent } \\
\text { number of cycles } \\
n_{1} \frac{N_{2}}{N_{1}}+n_{2}\end{array}$} & \multirow{2}{*}{$\begin{array}{c}\text { Cumulative } \\
\text { cycle ratio } \\
\qquad \Sigma \frac{n}{N}\end{array}$} & \multirow[t]{2}{*}{ Remarks } \\
\hline & Primary & Secondary & Primary $n_{1}$ & Secondary $n_{2}$ & & & \\
\hline B 17 & 40 & & 40000 & & & 0.8 & \\
\hline $\mathrm{B} 42$ & 38 & & 117500 & 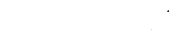 & & $1 \cdot 175$ & \\
\hline B44 & 38 & & 69000 & & & $0 \cdot 69$ & \\
\hline B 49 & 38 & & 91500 & & & 0.915 & \\
\hline B5.1 & 38 & & 64.500 & & & 0.645 & \\
\hline B 45 & 38 & & 76000 & & & $0 \cdot 76$ & \\
\hline B50 & 38 & & 74300 & & & 0.743 & \\
\hline B55 & 38 & & 74500 & & & $0 \cdot 745$ & \\
\hline B37 & 36 & & 242500 & & & $1 \cdot 243$ & \\
\hline B31 & 34 & & 336000 & & & 0.8 & \\
\hline $\mathrm{B} 41$ & 32 & & 1472000 & & & $1 \cdot 228$ & \\
\hline B51 & 31 & & 2348000 & & & u.821 & \\
\hline B32 & $30 \cdot 5$ & & 10155000 & & & & Not broken \\
\hline B46 & 30 & & 11200000 & & & & Not broken \\
\hline B36 & 29 & & 10935000 & & & & Not broken \\
\hline B53 & 38 & 40 & 50000 & 17500 & $425 C 0$ & 0.85 & \\
\hline B52 & 38 & 36 & 50000 & 85000 & 182500 & $0.93 €$ & \\
\hline B48 & 38 & 34 & 50000 & $1603 \mathrm{CO}$ & 370300 & 0.882 & \\
\hline B33 & 38 & 32 & 50000 & 111000 & 711000 & 0.592 & \\
\hline B38 & 38 & 31 & 50000 & 405200 & 1830200 & 0.542 & \\
\hline $\mathrm{B} 43$ & 38 & $30 \cdot 5$ & $50 \mathrm{co0}$ & 104400 & 5104400 & 0.51 & \\
\hline B34 & 38 & 36 & 80000 & 2000 & 160000 & 0.82 & \\
\hline B39 & 38 & 34 & $80 c 00$ & 1000 & $337 \mathrm{G00}$ & 0.802 & \\
\hline B35 & 38 & 32 & 80000 & 58400 & 1018400 & 0.848 & \\
\hline $\mathrm{B} 40$ & 38 & 31 & 80000 & 168200 & 2448200 & 0.859 & \\
\hline
\end{tabular}




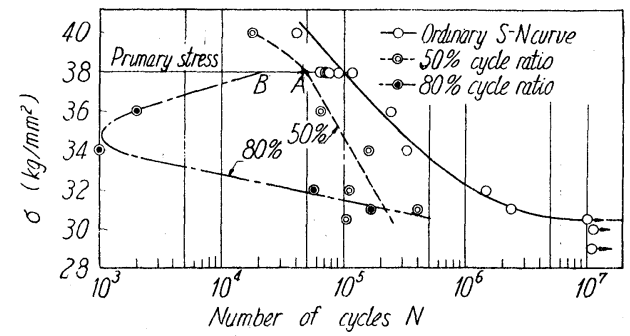

Fig. 14. Results on hard steel under high primary stress (1 st method).

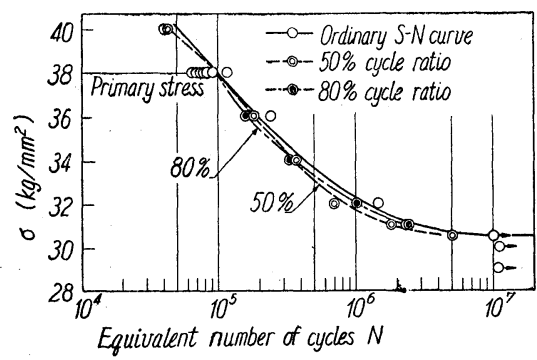

Fig. 15. Results on hard steel under high primary stress (2nd method).

よび Fig. 15 である．Fig. 14 は第 1 法により，Fig.15 は第 2 法により描的をのである。まず，Fig. 14 を 見るに，乙の場合 2 次応力が 1 次応力よりも大をい場 合で, かつ絽返数比 $80 \%$ 亿対する実驗結果が欠除して ロるが, 前と同様 1 次応力を与えた材料の $S-N$ 曲線 が 1 次応力の位置に和いていちじるしく屈曲するとと はないようである。まを，Fig. 15 より $\Sigma \frac{n}{N}$ の値は 2 次応力が 1 次応力より 小小るとをは $\Sigma \frac{n}{N}<1$ となり, 1 次応力の繰返数比 $80 \%$ の場合の方か $50 \%$ の場合より も概して $\Sigma \frac{n}{N}$ の值は大なるととも，軟鋼和よび半硬 鋼の場合と類似している。

\section{4 耐久限度に及ぼす影響について}

本実験は 1 次応力が 2 次応力に対する寿命飞及社す 影響を求めるととに重点を置的もので，1次応力が

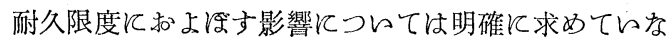
らが，第 1 法に従つて描いた各図より耐久限度に及法 す影響をもだいそい推察するととがでをる。での結果 は 1 次応力が比較的大なる場合は, 軟鋼, 半砸鋼, 硬
鋼のロずれと和いても例外なく耐久限度を低下せしめ， 1 次応力が比較的小宗当場合は概して耐久限度を上星 せしめるようである。民だし，1 次応力が比較的小な る場合で，硬鋼に $80 \%$ の繰返数比它与完を場合の夕耐 久限度はやや低下するように思われる。

\section{5. 結諭}

1. 2 段重複繰返応力をうける場合,一般に $\sum \frac{n}{N}=1$ 飞て破壊するといら考方方は成立しない。

2. 2 段重複繰返応力飞対する疲労試験結果を表わ す方法として, ことに提案した第 2 法, すなわち, 換 算繰返数をもつて表わす方法は, 奉験結果を $\sum \frac{n}{N}=1$ 飞よる結果と比較する場合, 一目瞭然となつてきわめ てわかりやすく便利である。

3. 第 1 法あるいは第 2 法によつて描いた曲線は, 軟鋼に和らては 1 次応力の位置にていちじるしい屈曲 を示すのに対し, 硬鋼て和いてはとのような屈曲を示 さない. 半硬鋼に执いては 1 次応力の小なる場合には 屈曲を示すが, 1 次応力の大なる場合屈曲を示さない。

4. 1 次応力が比較的小なる場合で, かつ 2 次応力 が 1 次応力より大なるときは, 硬鋼水ける繰返数比 $50 \%$ の場合を除を，概して $\sum \frac{n}{N}$ は 1 より大をく，か つ，炭素含有量の少な鋼ほぞ $\sum \frac{n}{N}$ の值は大をい。 また， 1 次応力が繰返数 $80 \%$ の場合の方が $50 \%$ の場合 よりも $\Sigma \frac{n}{N}$ の值が大き的。

5. 1 次応力が比校的小なる場合で, かつ, 2 次応 力が 1 次応力より小なるときは $\Sigma \frac{n}{N}$ の值は 1 より大 なるか，まをは，症とんど 1 亿等しい。

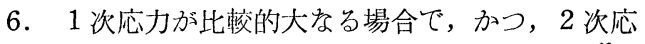
力が 1 次応力より大なるときは，軟鋼和らて $\sum \frac{n}{N}$ の值が 1 よりやや大となる以外は，ほ济 $\sum \frac{n}{N}$ の値は 1 亿等し々.

7. 1 次応力が比較的大なる場合で，かつ， 2 次応 力が 1 次応力より小娄与とは, 概して $\sum \frac{n}{N}$ の值は 1より小となる。そを゙し，軟鋼报よび半硬鋼に和々て 2 次応力が 1 次応力より少し小なるとさのみ $\Sigma \frac{n}{N}$ の值は 1 より大となる。また， 1 次応力絽返数比 $80 \%$ の場合の方が $50 \%$ の場合よりも $\Sigma \frac{n}{N}$ の値は概して大 きい。 